\title{
Magnetite microspheric particles from bright bolide of EN171101, exploded above the Trans-Carpathians mountains on Nov. 17, 2001
}

\author{
Klim I. Churyumov, ${ }^{1}$ Rudolf Ya. Belevtsev, ${ }^{2}$ Emlen V. Sobotovich, ${ }^{2}$ \\ Svitlana D. Spivak, ${ }^{2}$ Volodymyr I. Blazhko, ${ }^{2}$ \\ and Volodymyr I. Solonenko ${ }^{3}$ \\ ${ }^{1}$ Kyiv Shevchenko National University, \\ Box 04053, Observatorna str., 3, Kyiv, Ukraine \\ email: klim.churyumov@observ. univ.kiev.ua \\ ${ }^{2}$ Institute of environmental geochemistry of NAS and MES of Ukraine \\ ${ }^{3}$ Vinnytsia Kotsyubynskiy State Pedagogical University
}

\begin{abstract}
In 2007-2008 the authors found many magnetite microspheric particles in ground samples at the Trans-Carpathians mountains near the village of Tur'yi Remety. Their diameters are of $0.1-0.3 \mathrm{~mm}$ and they have $\mathrm{Ni}, \mathrm{Co}$ and $\mathrm{Cr}$ as chemical composition. We think that these particles are part of the bright bolide of EN171101 which exploded above Trans-Carpathians mountains on Nov. 17, 2001.
\end{abstract}

Keywords. meteors, meteoroids, bolide, microspherule, Earth

\section{Introduction}

In 2007-2008 mineralogical-geochemical researches were made in the region around the fall of the bright bolide of EN171101 (near the village of Tur'yi Remety) in TransCarpathians. The bolide of EN171101 (Tur'yi Remety) was photographed by the Czech and Slovakia chambers of the European bolide network (EN) on November, 17, 2001 at 16:52:44 UT (Spurny \& Porubchan, 2002). The length of the luminous track of the bolide reached $107 \mathrm{~km}$. It began at height of $81.4 \mathrm{~km}$ at $10 \mathrm{~km}$ to a south-west from the Ukrainian city of Dolina. The maximal brightness of $-18^{m}$ absolute star magnitude of the bolide was attained at the height of $20 \mathrm{~km}$. The bolide path finished at the height of $13.5 \mathrm{~km}$ near the village Tur'yi Remety. It is the deepest penetration of a bolide in the atmosphere of Earth, taken by a photographic chamber. Initial dynamic mass of bolides was estimated of $4500 \mathrm{~kg}$ and the eventual mass, after los by ablation was $370 \mathrm{~kg}$. The orbit was typical for bolides deeply penetrating into the atmosphere of Earth: $a=$ 1.33 A.U., $e=0.484, q=0.684$ A.U., $\omega=266.8^{\circ}, \Omega=235.4^{\circ}, i=7.4^{\circ}$. Searches of fragments of meteoroid with general eventual mass $370 \mathrm{~kg}$, made in Tur'yi Remety sat down in a district, unfortunately, did not give the positive results.

\section{Search of space matter from the bright bolide of EN171101 (Tur'yi Remety)}

Geologists Belevtsev R. Ya., Spivak S.D., Blazhko V.I. in 2007 made mineralogicalgeochemical researches in a pool of the river Tur'ya, and in 2008 these works were continued with the participation of Churyumov K.I. and Solonenko V.I. Presence of basalt and 


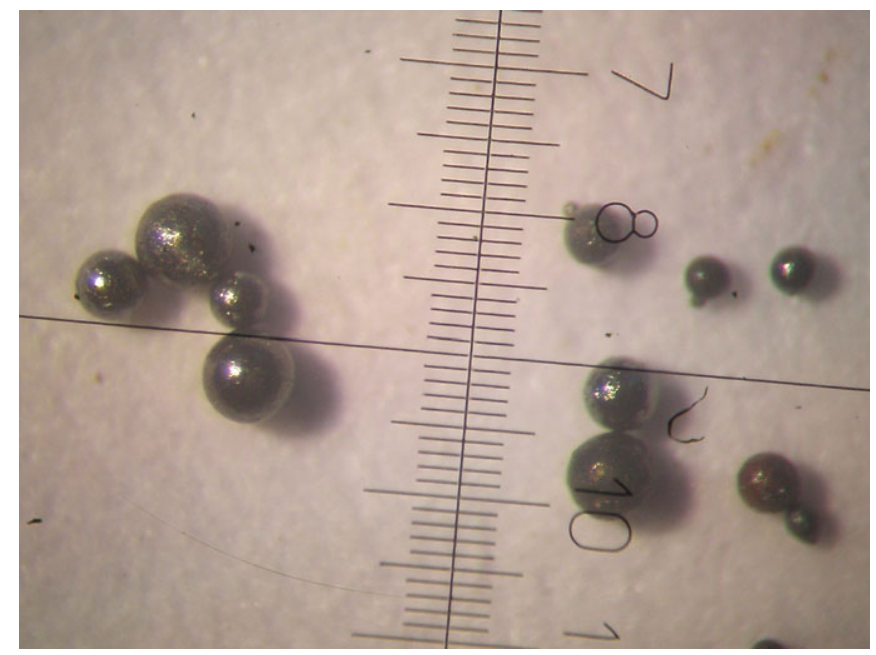

Figure 1. Magnetite microspherules that are possibly material from Bolide EN171101. The diameter of most microspherules is $0,3 \mathrm{~mm}$

other volcanic minerals, similar conduit ones, complicated the authentication of possible space matter from bolide of EN171101 in the studied Earth samples. One of the obvious substance features of the bolide EN17110 is magnetite microspherules in soil samples with diameters $0.1-0.3 \mathrm{~mm}$, a content of which is traced on magnetic fractions of concentrate and soil samples. These microspherules with spherical shape (and rarer elliptic or dropshaped form) were discovered with their primary concentration in the mangrove of the river Uzh between village Zarichevo and village Simer. Usually microspherules have different sizes in one sample, that allows to suppose their slow parachuting in the Earth's atmosphere after the explosion of the bolide of En171101 in windless weather (Fig. 1). Analogical microspherules were found out and investigated in the samples of soils, brought by L.A.Kulik from the region of the explosion of the Tunguska meteorite, by A.A.Yavnel in 1957, who with the help of the microchemical analysis found out the presence of nickel iron, that was a confirmation of the space origin of the material explored (Yavnel, 1957). Similar microspherules are described by E.V.Sobotovich (Sobotovich, 1976). Physical and chemical analyzes of magnetic fractions of the concentrate samples allowed to select the band of the promoted content in them $\mathrm{Ni}$, Co and $\mathrm{Cr}$, which is directed from Turichki-Lumshory to Simerka-Simer, i.e. approximately on 3-4 km to north-west than the published trajectory of flight of the En171101 Tur'yi Remety bolide (Spurny \& Porubchan, 2002). Presently physico-chemical and spectral analysis of the magnetite microspherules discovered by us is underway in order to confirm their space origin.

\section{References}

Sobotovich, E. V. 1976, Cosmic matter in the Earth's crust., 1, 159

Spurny, P., Porubchan, V. 2002, Proceedings of Asteroids, Comets, Meteors, (ESA-SP-500), pp. 269-272

Yavnel A. A. 1957, Astronomicheskii Journal, 34(5), 794 